\title{
A CASE STUDY ON IMPROVEMENT OF PLANT
}

\section{LAYOUT FOR EFFECTIVE PRODUCTION}

\section{S. N. WAGHMARE, P. M. SIRSAT, C. N. SAKHALE,}

\author{
S. M. AWATADE \& S. D. SHELARE
}

Assistant Professor, Mechanical Engineering Department, Priyadarshini

College of Engineering, Nagpur, Maharashtra, India

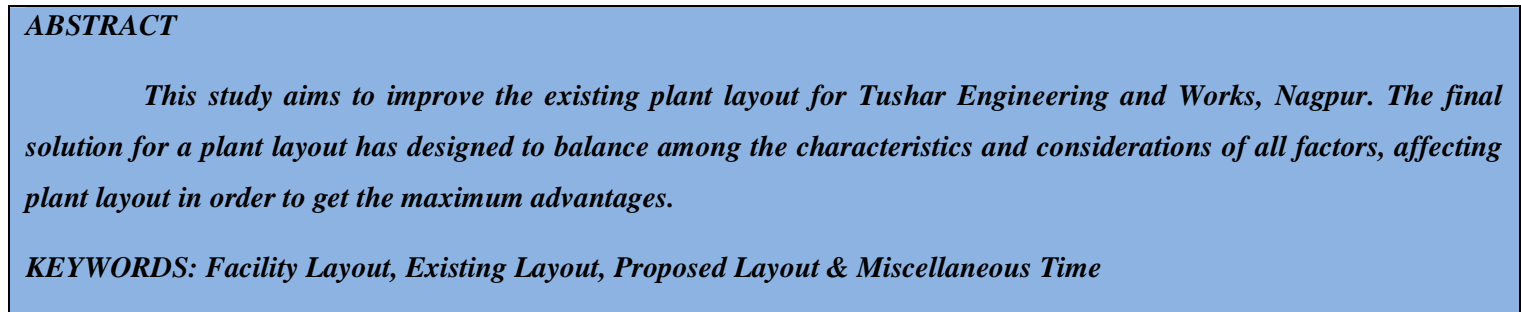

Received: Aug 14, 2017; Accepted: Sep 04, 2017; Published: Sep 13, 2017; Paper Id.: IJMPERDOCT201716

\section{INTRODUCTION}

Layout design involves a systematic physical arrangement of different departments, work stations, machines, equipments, storage areas and common areas, in a manufacturing industry. In today's competitive global environment, the optimum facility layout has become an effective tool in cost reduction, by enhancing the productivity. It has become very essential to have a well-organized plant layout, for all available resources in an optimum manner, to achieve the maximum returns.

\section{OBJECTIVE OF THE WORK}

To design a new plant layout with the aim of organization of machines and working areas, in the most efficient way and at the same time satisfactory and safety for the personnel doing the work.

\section{PROBLEM STATEMENT}

In the present work, existing facility layout of the industry has studied in detail, which shows unutilized spaces. The present layout supports $10 \%$ of the production, most of the processes for the products are the same, but the present layout has designed for the product that accounts for $10 \%$ of the total annual production and due to this, the material handling cost has increased for the product, that has $90 \%$ of the annual production.

\section{OVERVIEW OF EXISTING PLANT LAYOUT}

Figure 1, shows an existing plant layout. The material handling time is the important criterion for the analysis and selection of existing plant layout. For the development of new plant layout, following procedure has been followed:

Step 1: Summarization of interdepartmental moves of existing plant layout. 
Step 2: Simplifying moves and countermoves among departments.

Step 3: Preparation of the material handling cost matrix of the existing layout by multiplying the unit material handling costs by the number of moves among various departments.

Step 4: Calculation of total material handling cost of the existing layout.

Step 5: Changes in location of departments, that will reduce the number of moves and calculation of total material handling time.

\section{QRST Analysis}

Layout design begins with PQRST analysis, for the overall production activities. This includes P (product), Q (quantitative), R (routing), S (supporting) and T (time). The company manufactures various types of products. These products have more than 10 categories, which differ in physical size, structure (geometry), along with functional design and components. Thus, the existing layout dimensions, equipment, utilities, number of workers and machinery involved.

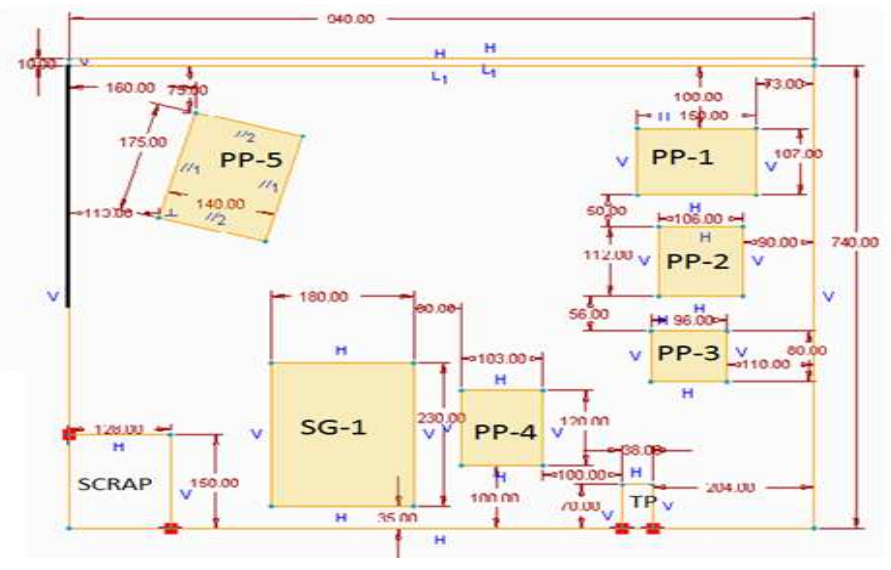

Figure 1: Existing Plant Layout

All dimensions are in feet.

\section{Materials Flow Analysis}

This step involves the analysis of the flow of materials, throughout the production. In this step, from-to chart is constructed, which represents the flow intensity and interaction between different production machines, as explained in figure 2 .

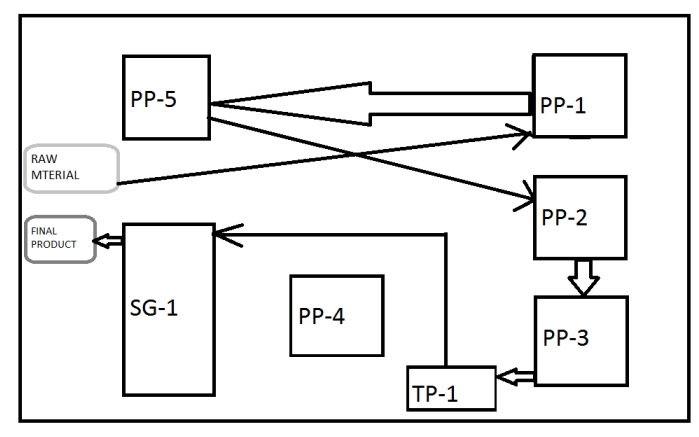

Figure 2: Material Flow Analysis 
PP-1 = Power Press (Shearing) PP-5 = Power Press (Bending)

PP-2 = Power Press (Piercing) TP-1 = Tapping Press

PP-3 = Power Press (Bending) SG-1 = Surface Grinding

PP-4 = Power Press (Piercing)

\section{PROPOSED PLANT LAYOUT}

\section{Design (Material Flow)}

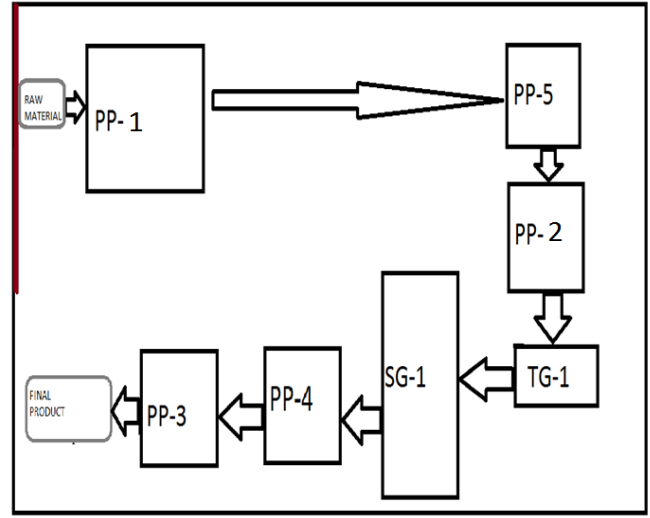

Figure 3: Design of New Layout (Material Flow)

\section{Proposed New Plant Layout}

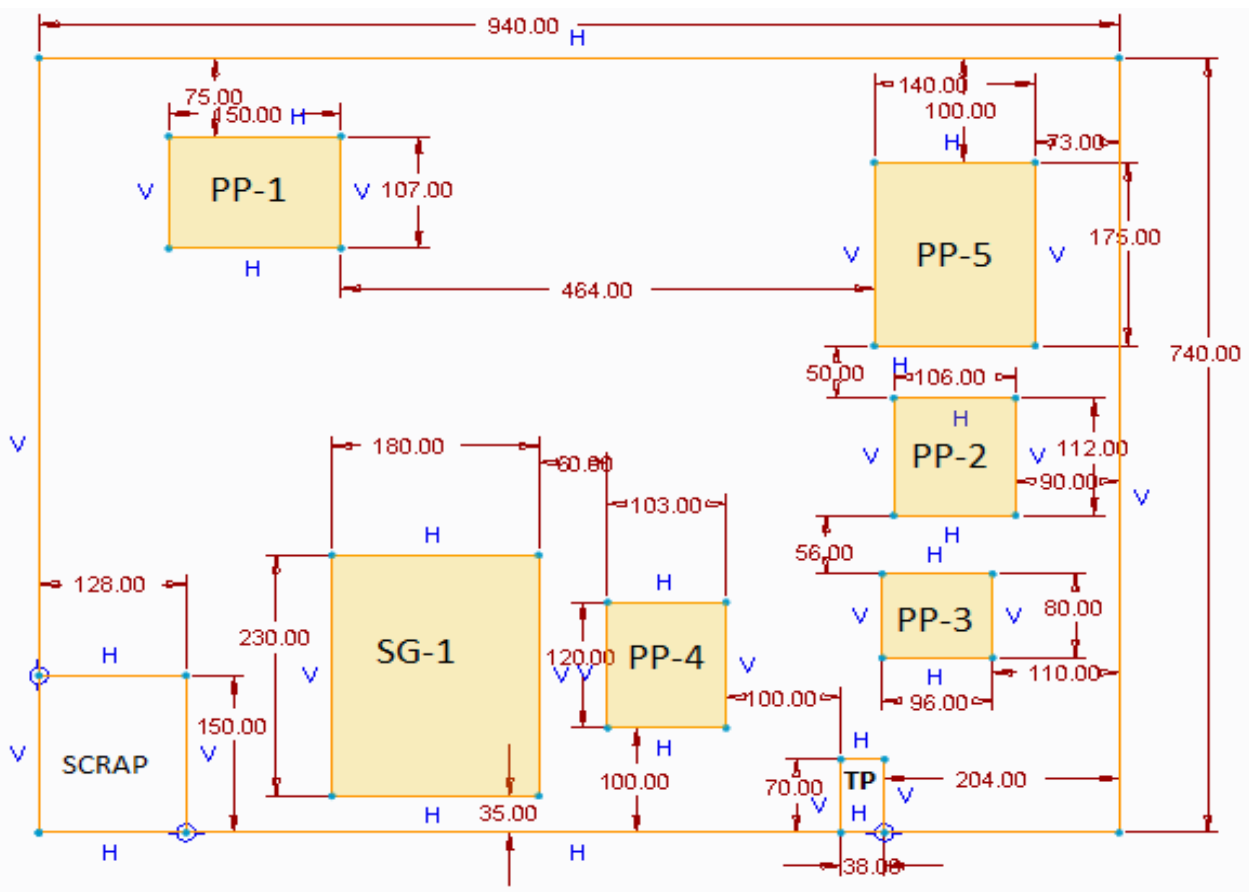

Figure 4: Proposed New Plant Layout

All dimensions are in feet. 


\section{EVALUATION METHOD}

Overall material flow minimization for productivity improvement and minimizing idle time, material flow has estimated for existing and proposed layouts.

Table 1: Time Calculation for Existing Plants Layout

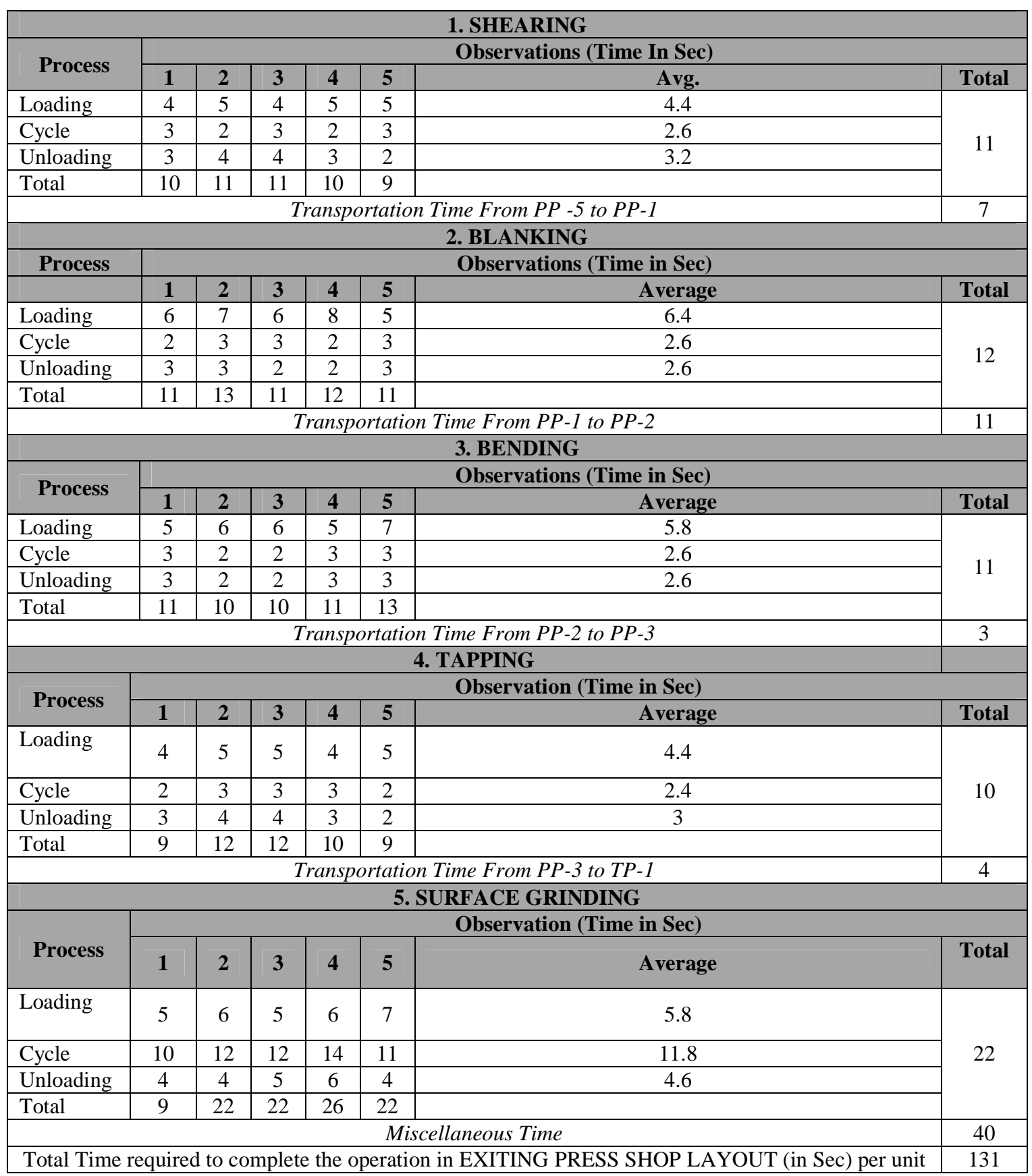


Table 2: Time Calculation for Proposed New Plant Layout

\begin{tabular}{|c|c|c|c|c|c|c|c|}
\hline \multicolumn{8}{|c|}{ 1. SHEARING } \\
\hline \multirow{2}{*}{ Process } & \multicolumn{7}{|c|}{ Observations (Time In Sec) } \\
\hline & 1 & 2 & 3 & 4 & 5 & Avg. & Total \\
\hline Loading & 4 & 5 & 4 & 5 & 5 & 4.4 & \multirow{4}{*}{11} \\
\hline Cycle & 3 & 2 & 3 & 2 & 3 & 2.6 & \\
\hline Unloading & 3 & 4 & 4 & 3 & 2 & 3.2 & \\
\hline Total & 10 & 11 & 11 & 10 & 9 & & \\
\hline \multicolumn{7}{|c|}{ Transportation Time From $P P-5$ to $P P-1$} & 7 \\
\hline \multicolumn{8}{|c|}{ 2. BLANKING } \\
\hline \multirow[t]{2}{*}{ Process } & & & & & & Observations (Time in Sec) & \\
\hline & 1 & 2 & 3 & 4 & 5 & Average & Total \\
\hline Loading & 6 & 7 & 6 & 8 & 5 & 6.4 & \multirow{4}{*}{12} \\
\hline Cycle & 2 & 3 & 3 & 2 & 3 & 2.6 & \\
\hline Unloading & 3 & 3 & 2 & 2 & 3 & 2.6 & \\
\hline Total & 11 & 13 & 11 & 12 & 11 & & \\
\hline \multicolumn{7}{|c|}{ Transportation Time From PP-1 to PP-2 } & 2 \\
\hline \multicolumn{8}{|c|}{ 3. BENDING } \\
\hline \multirow{2}{*}{ Process } & & & & & & Observations (Time in Sec) & \\
\hline & 1 & 2 & 3 & 4 & 5 & Average & Total \\
\hline Loading & 5 & 6 & 6 & 5 & 7 & 5.8 & \multirow{4}{*}{11} \\
\hline Cycle & 3 & 2 & 2 & 3 & 3 & 2.6 & \\
\hline Unloading & 3 & 2 & 2 & 3 & 3 & 2.6 & \\
\hline Total & 11 & 10 & 10 & 11 & 13 & & \\
\hline \multicolumn{7}{|c|}{ Transportation Time From PP-2 to PP-3 } & 3 \\
\hline \multicolumn{7}{|c|}{ 4. TAPPING } & \\
\hline \multirow{2}{*}{ Process } & & & & & & Observation (Time in Sec) & \\
\hline & 1 & 2 & 3 & 4 & 5 & Average & Total \\
\hline Loading & 4 & 5 & 5 & 4 & 5 & 4.4 & \multirow{4}{*}{10} \\
\hline Cycle & 2 & 3 & 3 & 3 & 2 & 2.4 & \\
\hline Unloading & 3 & 4 & 4 & 3 & 2 & 3 & \\
\hline Total & 9 & 12 & 12 & 10 & 9 & & \\
\hline \multicolumn{7}{|c|}{ Transportation Time From PP-3 to TP-1 } & 3 \\
\hline \multicolumn{8}{|c|}{ 5. SURFACE GRINDING } \\
\hline \multirow[b]{2}{*}{ Process } & \multicolumn{6}{|c|}{ Observation (Time in Sec) } & \\
\hline & 1 & 2 & 3 & 4 & 5 & Average & Total \\
\hline Loading & 5 & 6 & 5 & 6 & 7 & 5.8 & \multirow{4}{*}{22} \\
\hline Cycle & 10 & 12 & 12 & 14 & 11 & 11.8 & \\
\hline Unloading & 4 & 4 & 5 & 6 & 4 & 4.6 & \\
\hline Total & 9 & 22 & 22 & 26 & 22 & & \\
\hline \multicolumn{7}{|c|}{ Miscellaneous Time } & 15 \\
\hline \multicolumn{7}{|c|}{$\begin{array}{l}\text { Total Time required to complete the operation in the PROPOSED PRESS SHOP LAYOUT (in Sec) per } \\
\text { unit }\end{array}$} & 96 \\
\hline
\end{tabular}

\section{RESULTS}

The total time required to complete the operation per unit has reduced by $35 \mathrm{Sec}$.

Overall distance travelled (i.e. Material flow) during manufacturing has minimum.

The formation of logistic center eliminates delays, and minimizes transport because of its central location. For better utilization of space, inspection center is constructed. 


\section{CONCLUSIONS}

It has been found that, analysis of facility design, such as layout and material handling system is very important in a manufacturing industry. Proper analysis of existing layout design, could improve the performance of production lines. It could decrease bottleneck rate, minimize material handling cost, reduces idle time, raise the efficiency and utilization of labor, equipment and space.

\section{REFERENCES}

1. Balasundaram, Ashenafi Adugna, Sisay Abera, 'Improvement of Plant layout Design for Effective Production: A Case Study', International Journal of Innovative Research in Science, Engineering and Technology, Volume 5, Issue 11, November 2016.

2. Chandra Shekhar Tak and Mr. Lalit Yadav, Improvement in Layout Design using SLP of a small size manufacturing unit: A Case Study, IOSR Journal of Engineering (IOSRJEN), Volume 2, Issue 10, October 2012.

3. Amir J. Khan and D.J. Tidke, 'Designing Facilities Layout for Small and Medium Enterprises', International Journal of Engineering Research and General Science, Volume 1, Issue 2, December 2013.

4. W. Wiyaratn and A. Watanapa, Improvement Plant Layout Using Systematic Layout Planning (SLP) for Increased Productivity, International Journal of Mechanical, Aerospace, Industrial, Mechatronic and Manufacturing Engineering Volume 4, Issue 12, 2010.

5. Ms. Swati Jain and Mr. Tarun Kumar Yadav, Systematic Layout Planning: A Review of Improvement in Approach to Pulse Processing Mills, International Research Journal of Engineering and Technology (IRJET), Volume 4, Issue 5, May 2017.

6. Abhijeet S. Dhase and Prof. Ujwala Bairagi, 'Optimization of Quality and Productivity with Systematic Layout Planning', International Journal of Advance Research in Computer Science and Management Studies, Volume 4, Issue 10, October 2016.

7. Asifa Fitriani, Galih Prakoso and Anton Mulyono Azis, 'Facility Layout Improvement: Based on Safety and Health at Work and Standards of Food Production Facility', International Conference on Trends in Economics, Humanities and Management (ICTEHM'15) March 27-28, 2015 Singapore. 